\title{
AOR
}

Selected Papers of \#AolR2019: The $20^{\text {th }}$ Annual Conference of the Association of Internet Researchers Brisbane, Australia / 2-5 October 2019

\section{PERFORMING (IN)JUSTICE: THE CONTENTIOUS POLITICS OF DIGITALLY MEDIATED VISUALS}

In the past decade, Internet research has been marked by several studies addressing the digitally mediated nature of sociopolitical contentions in contemporary societies (Tufecki \& Wilson, 2012; Papacharissi, 2010), often insisting on how digital media technologies afford new ways for citizens to perform (in)justice in a connective (Bennett \& Segerberg, 2012) or reticular (Castells, 2015) fashion. Yet, if (in)justice and its performance are indeed increasingly digitally mediated, they are also increasingly visually mediated. The consideration that visuals play a constitutive part in mediating sociopolitical contentions is not new; key insights have already been provided in the fields of visual politics (Bleiker, 2018), visual culture (Mirzoeff, 1999) and visual sociology (Grady, 1996). These literatures invite researchers to move beyond text and pay attention to visual elements that are simultaneously the reflections and producers of important sociopolitical contentions. Indeed, visuals have politics, as their depictions (how and what they show or hide) and their intentions (what they aim or forfeit) are never neutral but always constructed and often productive. Visuals have politics because of the contentious processes through which they come to be and because of the material incidences they generate. On the one hand, visuals can be emancipatory when they allow marginalized groups to counter the hegemonic discourses promoted by the mainstream media or the state in which they no longer trust; on the other, they can also contribute to social injustices by reaffirming or reproducing power dynamics already at play.

In this panel, presenters are invited to reflect on the specific role of digital affordances and platform politics in sustaining the construction, circulation, and productiveness of politically contentious visuals (Bohr \& Sliwinska, 2018; Mortensen, 2017). Thus, in digitally mediated contexts, how are visuals produced and what forms of (in)justice can they perform? In the recent years, Internet scholars have started to address this question, notably, when studying the cultural and sociopolitical implications of Internet memes (Milner, 2016; Shifman, 2014). Taking memology as a starting point, panelists are invited to reflect on the many forms that digitally mediated visuals can assume (memes, graphs, pictures, icons, symbols, posters, graffiti, etc.) both across and beyond online platforms, as well as to examine their political nature and productiveness. Thus, this panel will ask: 1) how do digitally mediated visuals enact forms of (in)justice?; 2) what potentials or limitations do digitally mediated visuals generate for scholars who 
wish to understand broader sociopolitical contentions?; and 3) what conceptual and methodological tools should (Internet) scholars employ to study the contentious politics

of digitally mediated visuals (and with what ethical implications)?

To answer these questions, this panel brings together a transdisciplinary group of researchers (media and communication, international relations, cultural studies, discourse theory) in the hope of fostering rich discussions across disciplinary traditions. As shown below, panelists address a variety of sociopolitical topics across social media platforms (WhatsApp, Instagram, Facebook, Twitter), as well as across territories and cultures, topics that include: Black justice movements in the US; sexual racism in Latin America and Southeast Asia; conflicts over the representations of death in the Middle East; and transnational movements for trans rights activism. While these papers all engage with Internet research to investigate the contentious politics of digitally mediated visuals, they do so by drawing on several perspectives that seek to challenge hegemonic conceptions and discourses (decolonial studies, queer and feminist theories, non-Western literatures, literatures from the Global South, etc.). They also mobilize a series of qualitative or hybrid methods that track the trajectories of digitally mediated visuals to better understand their biographies and sociopolitical productiveness in the situated context of their emergence, methods that are of particular interest for the field of Internet studies given the ongoing critiques formulated against emerging trends in the automated visualizations of big (visual) data.

\section{References}

Bennett, W. L., \& Segerberg, A. (2012). The Logic of Connective Action: Digital Media and the Personalization of Contentious Politics. Information, Communication \& Society, 15(5), 739-768.

Bleiker, R. (Ed.). (2018). Visual Global Politics. Routledge.

Bohr, M., \& Sliwinska, B. (2018). The Evolution of the Image: Political Action and the Digital Self. Routledge.

Castells, M. (2015). Networks of Outrage and Hope: Social Movements in the Internet Age. John Wiley \& Sons.

Grady, J. (1996). The Scope of Visual Sociology. Visual Studies, 11(2), 10-24.

Milner, R. M. (2016). The World Made Meme: Public Conversations and Participatory Media. MIT Press. 
Mirzoeff, N. (1999). An Introduction to Visual Culture. London: Routledge.

Mortensen, M. (2017). Constructing, Confirming, and Contesting Icons: The Alan Kurdi Imagery Appropriated by \#humanitywashedashore, Ai Weiwei, and Charlie Hebdo. Media, Culture \& Society, 39(8), 1142-1161.

Olesen, T. (2015). Global Injustice Symbols and Social Movements. Springer.

Papacharissi, Z. (2010). A Private Sphere: Democracy in a Digital Age. Polity.

Shifman, L. (2014). Memes in Digital Culture. MIT press. 


\title{
AOR
}

Selected Papers of \#AolR2019:

The $20^{\text {th }}$ Annual Conference of the Association of Internet Researchers Brisbane, Australia / 2-5 October 2019

\section{OPERATIONALIZING DIGITAL ACTIVISM: THE ENDURING IMAGE OF TRAYVON MARTIN IN THE STRUGGLE FOR SOCIAL JUSTICE}

\author{
Kelly Lewis \\ Digital Media Research Centre, Queensland University of Technology
}

\section{Introduction}

Digitally mediated images that reveal overt acts of racist violence and brutality inflicted on Black bodies have become a persisting feature of contemporary visual culture in the US. This presentation explores the role digitally mediated images play in contemporary activism within popular social justice movements and examines how visual social media facilitate new ways of "resocializing the political" (Fenton, 2016). I do so through a case study on the 2012 killing of 17-year-old Black male Trayvon Martin, in Sanford, Florida, US. In his death, Trayvon has become the martyr for a new generation of Black activism (Gambino \& Laughland, 2015); his unjust killing served as the catalyst that gave rise to popular unrest through the \#JusticeForTrayvon campaign and brought into being a national conversation about police brutality, gun violence, and systematic racism against Black people that led to the Black Lives Matter (BLM) movement in 2013. The premise of this presentation is that digitally mediated images not only perform representational or illustrative functions but are also operationalized - as instruments and agents in activist practice, as products and producers of sociopolitical work - to render acts of police brutality and racial injustice visible in new ways, through which they create social identifications, antagonisms, and political contentions as part of their operational dynamics.

\section{\#JusticeForTrayvon: operationalizing (in)justice}

The objective of this presentation is to examine how Trayvon's image has been 1) appropriated posthumously in visual social media, 2) discursively placed in conversation with these movements, and 3) transformed across time as a contemporary vernacular of resistance and resilience in the ongoing struggle for Black social justice in the US. To do so, I employ the term "operative image" (Farocki, 2004) to argue digitally mediated images of Trayvon not only reflect sociopolitical realities, but play a performative and constitutive role in creating sociopolitical events and contentions. This transpires through processes of digital materiality and memetic trajectories where images frequently spread beyond the original forms and intentions of their producers, often 
operating against them in counter narratives. Through this framework, I investigate how images and their visual variations (herein collectively referred to as "images") are discursively constructed (repoliticized) and spread (resocialized) through the affordances of digital technologies to galvanize and mobilize individuals as part of an affective operation: the struggle for justice. I do this by establishing how digitally mediated images are not simply 'showing things', rather, they are 'doing things'. These effects are operationalized through communicative practice that entangles acts of commemoration, identity politicization, and activist mobilization to challenge dominant discourses and traditional ways of doing politics.

\section{"Trayvon lives on": the enduring image on Instagram}

This study relies on a discursive and iconographical analysis of manually selected Instagram posts containing the hashtag \#TrayvonMartin across a seven-year period (2012 -2019). Combining the scroll back method (Robards \& Lincoln, 2017) with online observation I chronologically traced the trajectory of images generated in response to Trayvon's killing. I selected posts (1819 images with textual commentary) for qualitative analysis on the basis of their recurrence and resonance. This data collection shows Trayvon has been depicted in portrait photographs and several variations including memes, artistic interpretations, and digital images of street protest. Through this I investigate the ways dominant and reoccurring digitally mediated images are operationalized - at different times, by different actors and in relation to different events - to perform radically different communicative action.

\section{Emergent practices in digital visual activism}

In the aftermath of Trayvon's killing numerous images of him were disseminated memetically online, across mainstream and social media, and offline, through embodied protest and creative appropriation. Results show these images seldom remained stable in their visual form and highlight how Trayvon's image became a site of struggle that shifted between competing narratives - both commemorative and contentious - that alternatively focused on depicting Trayvon as a saintly child victim, Black thug, everyday youth, or venerated martyr. To explore how these tropes emerged I traced the communicative practices and visual processes through which Trayvon's identity was posthumously transformed. Results point to the importance of identity-based discourses such as "we are all Trayvon Martin", "Trayvon could have been (me) (my son)", or "am I next" in building emotional narratives of shared precarity (Butler, 2009) and in the performance of affective expressions that invite collective identification and connection between dispersed audiences (Papacharissi, 2016). Results also indicate the visual construction of Trayvon as a socially recognizable identity and a resonant, yet contested, cultural subject operates through shared visual narratives and markers that blend iconographic genres (activist culture, religious traditions, art history, and Black visual culture). This suggests digitally mediated visuals become cultural products and political resources for social actors who operationalize them in acts of creative resistance and protest. As such, Trayvon's imagery becomes an operative framework through which other vulnerable and targeted bodies interpret, and perform resistance against, police brutality, racism and systematic violence against Black people in contemporary America as a shared and embodied experience of precarity. 


\section{Future directions for research}

The production and circulation of posthumous images depicting victims of unjust violence have emerged as recurring communicative practices within contemporary transnational activism, and reflects a new and ritualized protest dynamic: the digital mediation of death and martyrdom as a trope of resistance and solidarity. Extant literature addresses how images of unjust violence are used in environments of conflict, war, insurgency and counterinsurgency, yet, primarily abounds in journalism, media culture, and political visual communication. Internet research (Freelon et al., 2016) identifies the prominence and influence of digitally mediated visuals (with textual commentary) in spreading activist discourse on social media. Yet, big data approaches and textual analysis largely dominate the field (Highfield \& Leaver, 2016). Future qualitative approaches that facilitate deeper understandings of nuanced and emerging communicative practices - through native contextuality, temporal sensitivity, and agile observation - are needed. This analysis raises important implications for Internet researchers by establishing digitally mediated images are part of an operative process that has significant consequences: beyond representing contentious events, they critically restructure power relations, affect how discourses spread and dominant narratives are constructed (or challenged), and are operationalized to recruit bodies in collective action. Studying their operations in emerging configurations of contention and resistance - beyond Western contexts - is a critical site for inquiry in digital activism and visual politics research.

\section{References}

Butler, J. (2009). Frames of War: When Is Life Grievable? London; New York: Verso.

Farocki, H. (2004). Phantom Images, PUBLIC, 29, 12-22.

Fenton, N. (2016). Digital, Political, Radical (1st ed.). Oxford: Polity Press.

Freelon, D., Mcllwain, C., \& Clark, M. (2016). Beyond the Hashtags: \#Ferguson, \#Blacklivesmatter, and the Online Struggle for Offline Justice (Research Report). Center for Media \& Social Impact.

Gambino, L. \& Laughland, O. (2015, February 28). Three Years After Trayvon Martin, a New Civil Rights Movement Grows in Strength. The Guardian. [Online]. https://www.theguardian.com/us-news/2015/feb/27/trayvon-martin-new-civil-rightsmovement-grows-strength

Highfield, T. \& Leaver, T. (2016). Instagrammatics and Digital Methods: Studying Visual Social Media, From Selfies and GIFs to Memes and Emoji. Communication Research and Practice, 2(1), 47-62.

Lewis, K. (2019, October 2-5). Operationalizing Digital Activism: The Enduring Image of Trayvon Martin in the Struggle for Social Justice. Paper presented at AolR 2019: The $20^{\text {th }}$ Annual Conference of the Association of Internet Researchers. Brisbane, Australia: AolR. Retrieved from http://spir.aoir.org. 
Papacharissi, Z. (2016). Affective Publics and Structures of Storytelling: Sentiment, Events and Mediality. Information, Communication \& Society, 19(3), 307-324.

Robards, B., \& Lincoln, S. (2017). Uncovering Longitudinal Life Narratives: Scrolling Back on Facebook. Qualitative Research, 17(6), 715-730.

Lewis, K. (2019, October 2-5). Operationalizing Digital Activism: The Enduring Image of Trayvon Martin in the Struggle for Social Justice. Paper presented at AolR 2019: The $20^{\text {th }}$ Annual Conference of the Association of Internet Researchers. Brisbane, Australia: AolR. Retrieved from http://spir.aoir.org. 


\title{
AOR
}

Selected Papers of \#AolR2019:

The $20^{\text {th }}$ Annual Conference of the Association of Internet Researchers Brisbane, Australia / 2-5 October 2019

\section{SHARING IMAGES OF CHILDREN'S DEATH: POLITICS AND DIGITAL MEDIATION OF POSTHUMOUS ICONS}

\author{
Dr Helen Berents \\ School of Justice, Queensland University of Technology
}

Images of suffering and dead children are ubiquitous in representations of and engagements with situations of conflict or crisis. This presentation places media studies and visual politics in conversation with feminist international relations to offer theoretical insights on politically contentious images and takes seriously the circulation of images of dead children within spaces of public discourse. Encounters with global politics are saturated in the visual. Pollock argues that "[m]ediatized culture disseminates images of gross, persistent, dehumanizing agony caused by political violence and economic greed" (2012, p. 71). Mediatized cultures draw on many forms of visual media; this presentation focuses on photography and still visual images that are shared via Twitter. Images of children are iconic (Berents, 2016), a synecdoche for understanding a political event (Moeller, 2002). They draw on stereotypes about childhood to illustrate a conflict or crisis. Considering their ubiquitous nature - in part facilitated by social media platforms that allow the circulation of images without the filter of editorial desks - it is crucial to consider how the production and sharing of digitally mediated images of dead children become a way for actors to politically engage in conflicts or crisis.

This presentation examines how dead children circulate digitally as posthumous icons that mediate political discourse. It does this by examining the potential role of social media discourses in shaping political contentions. I examine two cases in which images of dead children rapidly spread on social media: the death of Syrian refugee toddler Alan Kurdi on a Turkish beach in 2015, and the deaths of nine-month-old Alyousef twins in the gas attack on Khan Sheikhoun, Syria in 2017. Both these cases prompted affective responses, but also contestation over appropriateness of sharing (Olesen, 2018). They both also prompted broader political considerations. To theorize these implications, this presentation analyses three key frames: the politics of images, the politics of visualizing childhood, and the politics of how they circulate via social media technologies. 
Firstly, a consideration of images of suffering children must be situated within a broader understanding of the role of images. Images are an affective site of politics. An attention to images of children sits within a tradition that recognizes that images are a form of representation, and that such representations both shape political and social spaces, but are also sites of politics themselves (Bleiker, 2001; Shapiro, 1988). Feminist and postcolonial scholars argue for the vital need for attention to self-reflective practices about positionality and privilege inherent in the production and circulation of these images. Sontag famously noted that photographs of the subjects of violence continues colonial practices of "exhibiting exotic — that is, colonized—human beings" in ways that are "oblivious to the considerations that deter such displays of our own victims of violence" (2003, p. 65). How these images are produced and shared must be critically evaluated in terms of our own differentiated positions of privilege and positionality (Berents, 2019, p. 7).

Secondly, which children are seen, where they appear, and when they are mourned also tells us a lot about how we perceive conflicts. Rarely asked to speak, their bodies become symbols of injustice or cruelty. Kate Manzo notes that the use of images of children in this way has a long colonial history $(2008$, p. 636). Such images can be understood as 'icons' (Hariman and Lucaites, 2007) that are constructed through public discourse (Mortensen, 2017). There is a hierarchy of childhood, evident in how these images are chosen for publication, and circulated, whereby certain kinds of bodies are able to be photographed in agony or violence, and others are not depicted (Berents, 2019, p. 11).

Thirdly, the nature of social media technologies affords for images to no longer be limited and directed to one audience, but to circulate globally. For example, while Twitter is a transnational platform, discourses on Twitter are still contained in different networks, with different audiences. When an image 'goes viral' as Kurdi and the Alyousef twins did, these conversations often encounter each other in challenging and contested ways. While "networked publics" (boyd, 2010) facilitate mass dissemination of information, what spreads remains dependent on the (uneven) underlying social structure of the network (Marlow, 2005). Additionally, these discourses are not limited to Twitter - nor do they always originate on Twitter - but are part of a broader assemblage of media, politics, culture and emotions that co-create and perpetuate certain narratives and framings within a global context.

To consider these three frames jointly, this presentation draws on established methodologies for visual research. Bleiker advocates "drawing on multiple, diverse and even incompatible methods" $(2015$, p. 877$)$ to tease out the political and social complexities of images. His proposed approach for considering the politics of images draws on Rose's work on visual methods (2016). This presentation focuses on two sites identified by Rose: that of circulation and audiencing to tease out the ways in which these images reflect uneven global power relations and contested political and social engagements (Rose 2016, 24-47). It explores the compositional and social modalities of these images in turn, through these two sites.

Berents, H. (2019, October 2-5). Sharing Images of Children's Death: Politics and Digital Mediation of Posthumous Icons. Paper presented at AoIR 2019: The $20^{\text {th }}$ Annual Conference of the Association of Internet Researchers. Brisbane, Australia: AolR. Retrieved from http://spir.aoir.org. 
Together, this exploration of particular cases, and attention to particular sites and modalities guide this presentation's two questions: what are the implications of the increasing ubiquity of visual representations children's deaths? And how do online platforms impact the uneven power relations and global social and political contestations over these kinds of images? The role that social media play in constructing and circulating images of children's death and suffering as contested affective objects deserve closer scrutiny.

\section{References}

Berents, H. (2016). "Hashtagging Girlhood: \#IAmMalala, \#BringBackOurGirls and Gendering Representations of Global Politics" International Feminist Journal of Politics. 18(4), 513-527.

Berents H. (2019). "Apprehending the 'Telegenic Dead': Considering Images of Dead Children in Global Politics'. International Political Sociology. online-first

Bleiker, R. (2015). "Pluralist Methods for Visual Global Politics". Millennium. 43(3), 872890.

boyd, d. (2010). "Social Network Sites as Networked Publics: Affordances, Dynamics, and Implications." In Networked Self: Identity, Community, and Culture on Social Network Sites, edited by Papacharissi, Z., 39-58. New York: Routledge.

Hariman, R., and Lucaites, J. L. (2003). "Public Identity and Collective Memory in US Iconic Photography: The Image of 'Accidental Napalm'." Critical Studies in Media Communication. 20(1), 35-66.

Manzo, K. (2008). "Imaging Humanitarianism: NGO Identity and the Iconography of Childhood". Antipode. 40, 637.

Moeller, S. D. (2002). "A Hierarchy of Innocence: The Media's Use of Children in the Telling of International News". Press/Politics. 7(1), 36-56.

Mortensen, M. (2017). "Constructing, Confirming, and Contesting Icons: The Alan Kurdi Imagery Appropriated by \#humanitywashedashore, Ai Weiwei, and Charlie Hebdo." Media, Culture, and Society. 39(8), 1142-61. 
Olesen, T. (2017). "Memetic Protest and the Dramatic Diffusion of Alan Kurdi". Media, Culture \& Society. 40(5), 656-672

Pollock, G. (2012). "Photographing Atrocity: Becoming Iconic?” In Batchen, G., Gidley, M. Miller, N. K., and Prosser, J. (eds). Picturing Atrocity: Photography in Crisis. London: Reaktion Books

Gillian. R. (2016). Visual Methodologies: An Introduction to the Interpretation of Visual Materials. London: Sage.

Shapiro, M. (1988). The Politics of Representation: Writing Practices in Biography, Photography and Policy Analysis. Madison: University of Wisconsin Press.

Sontag, S. (2003). Regarding the Pain of Others. London: Penguin. 


\title{
AOR
}

Selected Papers of \#AolR2019:

The $20^{\text {th }}$ Annual Conference of the Association of Internet Researchers Brisbane, Australia / 2-5 October 2019

\section{INJUSTICE SYMBOLS AND THEIR DIGITAL MEDIATION IN POSTHUMOUS TRANS RIGHTS ACTIVISM}

\author{
Dr David Myles \\ Digital Media Research Centre, Queensland University of Technology \\ Kelly Lewis \\ Digital Media Research Centre, Queensland University of Technology
}

\section{Introduction}

Since 2008, 2982 murders of trans and gender-diverse persons have been reported globally (TMMP, 2018). In response to this ongoing violence, there has been a surge in sociopolitical protests among activists to highlight the injustice of these deaths. While trans rights activism is not new, the development of digital media has transformed how groups mobilize transnationally and demand justice (O'Riordan, 2005). This presentation investigates the role that mourning and commemoration play in contemporary trans rights activism and examines how digital media sustain the development of these collective practices. To do so, we explore three case studies where the unjust death of a trans person was mobilized politically: Jennifer Laude, who was murdered by an American soldier in 2014 and whose death sparked protests for LGBTQ+ rights and against US military presence in the Philippines; Hande Kader, a Turkish activist who was raped and burnt in 2016 and whose death sparked the international \#HandeKaderSesVer Twitter campaign; and Marsha P. Johnson, a Black American trans rights activist who died from uncertain circumstances in 1992 and who has been the source of increased LGBTQ+ mobilization since the release of a 2017 Netflix documentary.

The right to mourn: mediating injustice symbols digitally

As argued by Butler (2009), grief is not always about emotional containment or coping mechanisms; rather, it can sustain important acts of resistance that make death politically productive. By engaging in collective acts of mourning and commemoration, trans rights activists and their sympathizers challenge dominant conceptions surrounding whose lives are deemed 'grievable' (Butler, 2009). These practices constitute acts of resistance as they contest systemic forms of violence and redress relations of power by claiming the right of trans persons to matter. Our objective is to 
show how these acts are performed through the development of shared communicative practices that often produce and circulate posthumous visuals. Our main argument is that trans rights movements increasingly construct 'injustice symbols' that are digitally mediated and used as strategies for political mobilization. Injustice symbols often relate to specific individuals set in situations where unjust suffering or precarity is representative of broader sociopolitical contentions (Olesen, 2015). Likewise, the deaths of Jennifer, Hande, and Marsha were all framed by activist groups as unjust events that illustrate transnational patterns in trans rights abuse. These commemorative practices not only contribute in humanizing queer subjects but also make grief politically potent by transforming these subjects into global injustice symbols.

For this presentation, we examine the role of digitally mediated memes in constructing posthumous symbols. Memes have become a reoccurring practice of visual politics and are increasingly employed for sociopolitical resistance (Shifman, 2014). Political memes aim to bypass the control shared by the state and mainstream media over the production and dissemination of authoritative content. Thus, memes that depict or symbolize the deceased become key resources for expressing state distrust and for conducting resistance against censorship (Shifman, 2014). Political memes become particularly potent in contemporary activist cultures when they harness digital media features, like hashtags, which play a significant role in constituting 'affective publics' posthumously (Papacharissi, 2015). As our analysis shows, each case study depicts the use of contextual hashtags that come to symbolize local grievances, while also underlining the use of prevalent hashtags (\#TransLivesMatter, \#JusticeFor..., etc.) that situate the production of posthumous visuals within a transnational movement for trans rights.

\section{Jennifer, Hande \& Marsha: a comparative analysis}

This research consists of a comparative case study that relies on the manual collection of a small dataset (Latzko-Toth et al., 2017). We opted for this qualitative and crossplatform method because of its adaptability; indeed, opting to trace the trajectories of visual elements made the pre-identification of a specific terrain or platform difficult. For each case, rather than focusing our analysis on a single platform, we identified key visual elements depicting or symbolizing the deceased. We then tracked these elements' recurrence on multiple platforms (Twitter, Instagram, Facebook), in mainstream media (television, documentaries, newspapers) and in street demonstrations (on paper posters, on graffiti), as well as documented their variations and political re-appropriations over time.

\section{Visual trends in posthumous trans rights activism}

While our case studies bring up and are shaped by important local issues (like pronationalist Filipino sentiment, Turkish anti-secularism, or anti-Black and queer police brutality in the US), the construction of these killings as injustice symbols also depicts trends in trans rights activism. In each case, ritualized forms of visual practices emerged posthumously as a motif of resistance and commemoration by using images of the deceased alongside hashtags like \#JusticeForJennifer, \#JusticeForHande, and 
\#JusticeForMarsha as an indication of solidarity, whether that injustice relates to the nature of the committed crimes (the particularly brutal killings of Jennifer and Hande for example) or to the inability of the legal system to treat these deaths fairly or effectively. The injustice lies in the consideration that transphobia played a direct (i.e. being a trans woman gets you killed) or indirect (i.e. sex work makes you more vulnerable to violent crimes) role in these deaths. To contest, join, and bring visibility to these injustices, activists developed shared communicative practices that gradually (re)constructed Jennifer, Hande, and Marsha as champions who symbolize the grievances of the LGBTQ+ movement, practices in which posthumous visuals played key organizing, affective, and deliberative functions.

\section{Queering online death studies}

Our analysis raises important implications for online death studies. So far, much of the literature has focused on proximal or collective forms of loss to understand how digital media have blurred the boundaries traditionally established between privacy and publicness, while often downplaying the politics of mourning (Myles et al., 2019). There also seems to be a significant divide in Internet studies between: a) death and mourning; and b) activism and political mobilization. This raises important issues regarding the presence of biases toward death in Western literatures, as the belief that mourning rituals and acts of political resistance ought to be studied separately assuredly comes from a place of white and cisheteronormative privilege. Thus, scholars who study online death and mourning would gain by engaging with queer and non-Western literatures to shine a light on their own biases toward death and mourning whether or not they work on activism or queer deaths, as the question of who is allowed or denied the right to mourn or be mourned is always already political.

\section{References}

Butler, J. 2009. Frames of War: When is Life Grievable? London: Verso.

Latzko-Toth, G., Bonneau, C., \& Millette, M. (2017). Small Data, Thick Data: Thickening Strategies for Trace-based Social Media Research. The SAGE Handbook of Social Media Research Methods, 199-214.

Myles, D., Cherba, M. \& F. Millerand. (2019). Situating Ethics in Online Mourning Research: A Scoping Review of Empirical Studies. Qualitative Inquiry, 25(3), 289-299.

O'Riordan, K. (2005). Transgender Activism and the Net: Global Activism or Casualty of Globalisation. In de Jong, W., Shaw, M. \& N. Stammers (Eds). Global Activism, Global Media, London: Pluto Press, 179-193.

Olesen, T. (2015). Global injustice Symbols and Social Movements. New York: Palgrave Macmillan.

Myles, D. and Lewis, K. (2019, October 2-5). Injustice Symbols and Their Digital Mediation in Posthumous Trans Rights Activism. Paper presented at AolR 2019: The 20 $0^{\text {th }}$ Annual Conference of the Association of Internet Researchers. Brisbane, Australia: AolR. Retrieved from http://spir.aoir.org. 
Papacharissi, Z. (2015). Affective Publics: Sentiment, Technology, and Politics. Oxford University Press.

Shifman, L. (2014). Memes in Digital Culture. Cambridge: MIT press.

Trans Murder Monitoring Project. (2018). TMM Update Trans Day of Remembrance 2018. [Online]. https://transrespect.org/en/tmm-update-trans-day-of-remembrance$\underline{2018 /}$ 


\title{
AOR
}

Selected Papers of \#AolR2019:

The $20^{\text {th }}$ Annual Conference of the Association of Internet Researchers Brisbane, Australia / 2-5 October 2019

\section{THE CURATED LIFE OF AN ONLINE BRIDE: UNPACKING THE PARADOXICAL VISUALIZATION OF AGENTIC FEMININITY ON YOUTUBE}

\author{
Dr Earvin Charles B. Cabalquinto \\ School of Communication and Creative Arts, Deakin University \\ Digital communication technologies have played a crucial role in connecting migrants \\ with their homeland. In the context of Philippine migration, previous studies have \\ showcased how migrants utilize an array of mobile devices and networked \\ communication platforms in sustaining long-distance relationships (Madianou \& Miller, \\ 2012; Parreñas, 2005). However, a research gap exists in unraveling how migrants \\ utilize online platforms to exercise agency across networked and intimate spaces by \\ developing visual content. In the landscape of Philippine female migration, and its \\ transformation through the affordances of digital media technologies, this presentation \\ examines how the visual construction of the gendered, racialized and class-based body \\ of a Filipina 'marriage migrant' on YouTube enacts sociocultural contentions over \\ agentic femininity within the broader context of global interracial marriages. Ultimately, I \\ argue that these contentions shape the provision of 'lived activism' (Bonifacio, 2009) of \\ migrant women into a constrained, negotiated and consumerist modality.
}

As part of a broader project that investigates the mediation of intimacy through matchmaking platforms among Filipino women, this presentation unravels how Rhaze, a Filipina migrant, exercises agentic femininity by curating and displaying her intimate relationship with her Australian husband on YouTube. Rhaze was chosen as a case study for this presentation for two reasons. First, her YouTube channel, Simply Rhaze, is one of the most popular YouTube channels showcasing a Filipina migrant in Australia. Since 2012, it has amassed a following of more than 450 thousand subscribers and garnered over 85 million views. Second, Rhaze, as a lifestyle and beauty vlogger, capitalizes on visibilizing her intimate relationship with her Australian partner, which typically draws viewers and subscribers, as well as negative audiences. In one of her most viewed videos, she talks about how she met her Australian partner through the dating website Filipino Cupid, which paved the way for her migration to Australia through a partner visa and subsequent marriage to her partner in 2017.

Cabalquinto, E. C. B. (2019, October 2-5). The Curated Life of an Online Bride: Unpacking The Paradoxical Visualization of Agentic Femininity on YouTube. Paper presented at AolR 2019: The $20^{\text {th }}$ Annual Conference of the Association of Internet Researchers. Brisbane, Australia: AolR. Retrieved from http://spir.aoir.org. 
Rhaze's love story received coverage across media channels including ABS-CBN, one of the largest television networks in the Philippines. To date, her YouTube channel offers over 1000 videos situated across a variety of genres, including makeup tutorials, Q\&As, confessional talks, travels, and so forth. Ultimately, I argue that the playfulness and creativity of Rhaze's digitally mediated visuals embody the paradoxes of global interracial marriages, as accessed and interpreted by a 'digital intimate public' (Dobson, Robards, \& Carah, 2018).

For this presentation, I mobilize Rhaze's YouTube channel as a case study to understand how she uses a visual-based platform to counter dominant depictions of Filipino women in mainstream media, as well as explore some of the paradoxes that these depictions entail in terms of agentic femininity and citizenship. In the first instance, I critically reflect on agentic femininity as a strategy to challenge the stigma surrounding the representation of non-white women in interracial relationships. Historically, Filipino women have been stereotyped as 'mail-order brides' or as women from poor socioeconomic backgrounds, who usually marry white men to migrate overseas and escape poverty. These women are normally 'ordered' through catalogues and letters (Tolentino, 1996). In Australia, the influx of Filipino marriage migrants increased during the relaxation of the White Australia Policy (Espinosa, 2017). Filipino women have since become susceptible to discrimination and 'cultural othering' in physical spaces (Aquino, 2018; Espinosa, 2017; Roces, 2003) or through the media as prominently reflected in the representation of a Filipina in Priscilla Queen of the Desert (Laforteza, 2006). Ultimately, the stigma of mail-order brides has become synonymous to non-white (Bonifacio, 2009; Roces, 2003). Despite such contentions, Filipino marriage migrants still assert their agency in many ways (Bonifacio, 2009; Roces, 2003).

I argue that visual productions on YouTube can be understood as 'lived activism', or as practices that allow migrant women to navigate the structural barriers they face within interracial relationships (Bonifacio, 2009). In this specific case, Rhaze first depicts herself as a professional, educated, tech savvy, and proactive woman, an image that undermines the stereotypical depiction of a mail-order bride. Second, she showcases her ability to forge networks with other Filipina women, who are also married to Australian men. This arrangement provides her the ability to deal with life overseas. Third, she speaks Tagalog to remain grounded in her Filipino identity (Bonifacio, 2009) and establish connection to her viewers. Lastly, she exudes confidence in interacting with her Australian husband in various situations. By depicting these different personal capacities online, she exerts agency and establishes authenticity (Raun, 2018) to constitute intimate publics and counter dominant racial and gender narratives.

Yet, as my analysis points out, Rhaze also often performs emotional and affective labor, depictions which align with heteronormative systems in ways that reaffirm how online performances and their visual depictions are highly gendered (Banet-Weiser, 2012; Duffy, 2017). These performances can also be understood as being the results of conformity to a form of sexualized citizenship that is often bestowed upon migrant

Cabalquinto, E. C. B. (2019, October 2-5). The Curated Life of an Online Bride: Unpacking The Paradoxical Visualization of Agentic Femininity on YouTube. Paper presented at AolR 2019: The $20^{\text {th }}$ Annual Conference of the Association of Internet Researchers. Brisbane, Australia: AolR. Retrieved from http://spir.aoir.org. 
women (Espinosa, 2017). In this specific case study, as a migrant woman, Rhaze seemingly repays the gift of Australian citizenship by delivering affective and reproductive labor in a patriarchal household (Lam \& Yeoh, 2004). Paradoxically, to navigate a constrained space warrants an agentic femininity that positions neoliberal subjectivity in a market economy (Banet-Weiser, 2015). A sense of empowerment is operationalized through the commodification and visual depiction of everyday life and of an intimate relationship. As such, a migrant bride who moves across physical and networked spaces can be placed in paradoxical situations that are both enabled and constrained by networked and marketized environments.

\section{References}

Aquino, K. (2018). Racism and Resistance Among the Filipino Diaspora: Everyday Antiracism in Australia. Routledge: London.

Banet-Weiser, S. (2015). Keynote Address: Media, Markets, Gender: Economies of Visibility in a Neoliberal Moment. Communication Review, 18(1), 53-70. doi:10.1080/10714421.2015.996398

Bonifacio, G. L. A. T. (2009). Activism From the Margins; Filipino Marriage Migrants in Australia. Frontiers - A Journal of Women's Studies, (3), 142.

Dobson, A. S., Robards, B., \& Carah, N. (2018). Digital Intimate Publics and Social Media: Towards Theorising Public Lives on Private Platforms. In A. S. Dobson, B.

Robards, \& N. Carah (Eds.), Digital Intimate Publics and Social Media. 3-27. Switzerland: Palgrave Macmillan.

Espinosa, S. A. a. (2017). Sexualised Citizenship: A Cultural History of PhilippinesAustralian Migration. Gateway East, Singapore: Palgrave MacMillan.

Laforteza, E. (2006). What a Drag! Filipina/White Australian Relations in the Adventures of Priscilla Queen of the Dessert. ACRAWSA e-journal, 2(2), 1-18.

Lam, T., \& Yeoh, B. S. A. (2004). Negotiating 'Home' and 'National Identity': ChineseMalaysian Transmigrants in Singapore. Asia Pacific Viewpoint, 45(2), 141-164. doi:10.1111/j.1467-8373.2004.00235.x 
Madianou, M., \& Miller, D. (2012). Migration and New Media: Transnational Families and Polymedia. Abingdon, Oxon: Routledge.

Parreñas, R. S. (2005). Long Distance Intimacy: Class, Gender and Intergenerational Relations Between Mothers and Children in Filipino Transnational Families. Global Networks, 5(4), 317-336.

Raun, T. (2018). Capitalizing Intimacy: New Subcultural Forms of Micro-celebrity Strategies and Affective Labour on YouTube. Convergence, 24(1), 99-113.

Roces, M. (2003). Sisterhood is Local: Filipino Women in Mount Isa. In N. Piper \& M. Roces (Eds.), Wife or Worker?: Asian Women and Migration. 71-100. Lanham, MD: Rowman \& Littlefield.

Tolentino, R. B. (1996). Bodies, Letters, Catalogs: Filipinas in Transnational Space. Social Text, (48), 49-76. doi:10.2307/466786 


\title{
AOR
}

Selected Papers of \#AolR2019:

The $20^{\text {th }}$ Annual Conference of the Association of Internet Researchers Brisbane, Australia / 2-5 October 2019

\section{MISOGYNY ON WHATSAPP: EXAMINING THE METAPHOR OF 'DIRT’ IN MEMES ABOUT VENEZUELAN MIGRANT WOMEN IN COLOMBIA}

\author{
Dr Ariadna Matamoros-Fernández \\ Digital Media Research Centre, Queensland University of Technology \\ Dr Carlos Estrada Grajales \\ Civil Engineering and Built Environment, Queensland University of Technology
}

Women as scapegoats of the Venezuelan migration crisis

This presentation examines the contentious politics involved in the creation and sharing of WhatsApp memes about Venezuelan migrant women in Colombia. We first examine the xenophobic trope "migrant as pollutant" (Cisneros, 2008) articulated through these visual contents to then argue that such memes are actually generators of "dirt" in shared spaces.

Venezuela is experiencing deepening sociopolitical and economic unrest due to the deterioration of internal and external political relations, and a significant drop in the country's oil production. This has created a humanitarian crisis with a shortage of essential supplies, economic hyperinflation, and the forced migration of more than 3 million citizens (UNHCR, 2018). A majority of migrants have fled to Colombia - leading to an unprecedented spike in sociopolitical tensions - with some Venezuelans becoming targets of dehumanizing rhetoric, including sexists, misogynistic and xenophobic contents that circulated on digital platforms among other spaces (Guerrero Duque, 2018).

While much international attention is focused on Venezuela's political unrest, there is scarce information about how social and political contentions play out against migrant Venezuelan women in Colombia, who are currently subjects of violence (Bustos \& Granados, 2019; Zulver, 2019). Venezuelan women crossing into Colombian cities have been attacked on the grounds of being "dirty foreigners" (Zulver, 2019). This taps into the long-running xenophobic trope of portraying migrants as physically and morally polluting society (Cisneros, 2008), and into the misogynist trope of holding female

Matamoros-Fernández, A. and Estrada-Grajales, C. (2019, October 2-5). Misogyny on WhatsApp: Examining The Metaphor of 'Dirt' in Memes About Venezuelan Migrant Women in Colombia. Paper presented at AolR 2019: The $20^{\text {th }}$ Annual Conference of the Association of Internet Researchers. Brisbane, Australia: AoIR. Retrieved from http://spir.aoir.org. 
bodies to be "improper interference" in public spaces (Koning, 2014). In this presentation we appropriate these xenophobic and misogynistic tropes to argue that the practice of creating and sharing discriminatory memes about Venezuelan women on WhatsApp constitutes material "dirt", and that they culturally pollute shared spaces, especially because memes also migrate from private groups to other more public platforms like Facebook pages and Twitter.

To study this, we collect WhatsApp memes for discussion during interviews with Colombian organizations involved in promoting migrant's and women's rights. These memes 'humorously' portray Venezuelan women both as 'dirty' and as provoking libidinous impulses among men. The visual contents depict female bodies as hypersexualized and link migrant women's flesh to the moral and physical pollution of the space. We argue that these sociotechnical depictions of Venezuelan female bodies are highly discriminatory and awaken "gendered fears of pollution" (Koning, 2014). We are also interested in examining, through interviews with NGOs and organizations working with women and migrants in Colombia, how everyday engagements with these memes have the potential to disrupt 'microspaces' of conviviality (Wessendorf, 2016) between Venezuelan immigrants and Colombian neighbors.

\section{Memetics, online misogyny, and WhatsApp}

Digital media platforms aggravate existing patterns of online misogyny and introduce new abusive dynamics against women (Dragiewicz et al., 2018). Evidence also suggests these same platforms are useful tools for responding to sexism and abuse (Southworth et al., 2005). While there is research on the specific dynamics of online misogyny on Reddit, Twitter, YouTube, 4chan and 8chan (Massanari, 2015; Marwick \& Lewis, 2017), literature has disregarded how misogyny and abuse against women unfold in other platforms with high penetration rates in developing countries. This is the case of WhatsApp, which has emerged as one of the world's fastest-growing platforms and is the preferred app in countries including India, Indonesia, Brazil, Colombia, and South Africa.

In Colombia, WhatsApp is the most used platform with levels of $90 \%$ penetration (MINTIC, 2018). WhatsApp usage includes interpersonal communications, collaborative work, the spreading of commercial or political contents, and, in some cases, the circulation of negative and harmful messages and content. WhatsApp groups, which allow personal connections and conversations between up to 256 users, facilitate a brevity of collective sociability positioning the app more as a social network than a simple text-messaging service. Analysis of online misogyny must examine the sites where everyday online socialization happens in a specific national context; which in Colombia inevitably includes WhatsApp. We propose to study how memetic media contributes to normalizing long-standing biases in society (Milner, 2016) in the platformspecific context of WhatsApp and within Colombia.

Matamoros-Fernández, A. and Estrada-Grajales, C. (2019, October 2-5). Misogyny on WhatsApp: Examining The Metaphor of 'Dirt' in Memes About Venezuelan Migrant Women in Colombia. Paper presented at AolR 2019: The 20 ${ }^{\text {th }}$ Annual Conference of the Association of Internet Researchers. Brisbane, Australia: AolR. Retrieved from http://spir.aoir.org. 


\section{The need for new methods to study encrypted apps}

Methodological challenges exist for studying the flow of visual contents on WhatsApp, which this project seeks to address. Currently, WhatsApp has been studied using traditional methods mainly, including interviews, surveys, and ethnographic research. WhatsApp's end-to-end encryption does not allow researchers access to content shared on the app. We propose a method to collect data on WhatsApp that has already been tested by news outlets to fact check the circulation of misinformation (Hazard Owen, 2018). Our method involves the set-up of a WhatsApp account, which serves as a depository of memes. We circulated the number of this account through our WhatsApp networks in Colombia, and received memes on a regular basis during our one-month data collection period (February 2019). Any WhatsApp user willing to participate was able to send memes to the researchers' WhatsApp account.

While this presentation does not claim that the data collection is representative of all memes shared on WhatsApp about Venezuelan migrant women in Colombia, its method aims to collect enough memes (more than 100) to elaborate a taxonomy. The visual content collected will serve as material for discussion in semi-structured interviews with relevant NGOs representatives and journalists working on women's rights and digital technologies in Colombia, which constitutes the second phase of our data collection for this project.

\section{References}

Bustos, N., \& Granados, I. (2019, February 27). Georgina Pérez: "Ser de Venezuela no me hace ni mejor ni peor persona." El Espectador.

Cisneros, D. (2008). Contaminated Communities: The Metaphor of "Immigrant as Pollutant" in Media Representations of Immigration. Rhetoric \& Public Affairs, 11(4), 569-601.

Dragiewicz, M., Burgess, J., Matamoros-Fernández, A., Salter, M., Suzor, N. P., Woodlock, D., \& Harris, B. (2018). Technology Facilitated Coercive Control: Domestic Violence and the Competing Roles of Digital Media Platforms. Feminist Media Studies, 18(4), 609-625.

Guerrero Duque, N. (2018, April 11). Ya estuvo bueno con los memes de las venezolanas. Vice.

Hazard Owen, L. (2018, June 1). WhatsApp is a Black Box for Fake News. Verificado 2018 is Making Real Progress Fixing That. Nieman Lab.

Matamoros-Fernández, A. and Estrada-Grajales, C. (2019, October 2-5). Misogyny on WhatsApp: Examining The Metaphor of 'Dirt' in Memes About Venezuelan Migrant Women in Colombia. Paper presented at AolR 2019: The 20 th Annual Conference of the Association of Internet Researchers. Brisbane, Australia: AolR. Retrieved from http://spir.aoir.org. 
Koning, A. D. (2014). Gendered Fears of Pollution: Traversing Public Space in Neoliberal Cairo. In E. Dürr \& R. Jaffe (Eds.), Urban Pollution: Cultural Meanings, Social Practices. 103-122. Berghahn Books.

Marwick, A. E., \& Lewis, R. (2017). Media Manipulation and Disinformation Online. Data \& Society.

Massanari, A. (2015). \#Gamergate and The Fappening: How Reddit's Algorithm, Governance, and Culture Support Toxic Technocultures. New Media \& Society, 19(3), 329-346.

Milner, R. M. (2016). The World Made Meme. MIT Press.

MINTIC. (2018, March 20). Cuáles son las redes sociales que más se usan en su región? MINTIC.

Southworth et al. (2005). A High-Tech Twist on Abuse: Technology, Intimate Partner Stalking, and Advocacy. Violence against Women Online Resources.

UNHCR. (2018, November 8). Number of Refugees and Migrants from Venezuela Reaches 3 Million. UNHCR.

Wessendorf, S. (2016). Settling in a Super-Diverse Context: Recent Migrants' Experiences of Conviviality. Journal of Intercultural Studies, 37(5), 449-463.

Zulver, J. (2019, February 26). At Venezuela's Border with Colombia, Women Suffer Extraordinary Levels of Violence. The Washington Post.

Matamoros-Fernández, A. and Estrada-Grajales, C. (2019, October 2-5). Misogyny on WhatsApp: Examining The Metaphor of 'Dirt' in Memes About Venezuelan Migrant Women in Colombia. Paper presented at AolR 2019: The $20^{\text {th }}$ Annual Conference of the Association of Internet Researchers. Brisbane, Australia: AolR. Retrieved from http://spir.aoir.org. 